\title{
Gas chromatography-mass spectrometry metabolomics of goat milk with different polymorphism at the $\alpha_{\mathrm{s} 1}$-casein genotype locus
}

\author{
Pierluigi Caboni, ${ }^{* 1}$ Antonio Murgia, ${ }^{*}$ Alessandra Porcu, ${ }^{*}$ Martina Demuru, ${ }^{*}$ Giuseppe Pulina, $\dagger$ \\ and Anna Nudda† \\ *Dipartimento di Scienze della Vita e dell'Ambiente, Università di Cagliari, Cagliari, CA 09124, Italy \\ †Dipartimento di Agraria, Sezione di Scienze Zootecniche, Università di Sassari, Sassari 07100, Italy
}

\begin{abstract}
Hyphenated gas chromatography-mass spectrometry (GC-MS) and multivariate data analysis techniques were used to uncover milk metabolite differences in different $\alpha_{\mathrm{S} 1}$-casein genotypes of goats. By a discriminant GC-MS metabolomics approach, we characterized milk polar metabolites of 28 goats. Animals were selected on the basis of their genotypes as 7 goats classified heterozygous for weak or null alleles, 5 for the genotype $E E$, 9 for the genotypes $A E$ and $B E$, and finally 7 for the strong genotype $A A$. Low molecular weight polar metabolite profile was tightly related to the different goat genotypes, milk production, and protein levels. Results of multivariate statistical analysis of GC-MS data demonstrate that different heterozygous and homozygous genotypes expressed different metabolites such as citric and aconitic acid for the strong allele class with different sugars and polyols for the weak class.
\end{abstract}

Key words: multivariate analysis, genotypes, aconitic acid, levoglucosan

\section{INTRODUCTION}

Among many analytical hyphenated platforms, gas chromatography coupled to mass spectrometry has been shown capable of identifying and quantifying milk hydrophilic metabolites (Scano et al., 2014; Pisano et al., 2016). A metabolomics approach coupled with multivariate statistical analysis (MVA) has been easily used to explore relationships between food metabolomes. These techniques can be also used to evaluate nutraceuticals with nutritional and physiological properties of dairy products for quality control, amelioration, and breeding. To date, little research has been done on the use of metabolite profiling of goat

Received October 19, 2015.

Accepted May 1, 2016.

${ }^{1}$ Corresponding author: caboni@unica.it milk and elucidation of the relationship between metabolome and nutraceuticals. Goat milk is a source of bioactive compounds that could be used as functional ingredients for products beneficial to human nutrition (Le Parc et al., 2014; Zhou and Makrides, 2014) and shows various health-promoting properties (Jirillo and Magrone, 2014). In contrast, Ballabio et al. (2011) recently reported a study of goat milk allergenicity as a function of $\alpha_{S_{1}}$-casein genetic polymorphism. In this context, goat milk has been tested as an alternative to cow milk in subjects who show intolerance or allergy to cow milk protein (Carroccio et al., 2000; Hosking et al., 2000; Bevilacqua et al., 2001). The caseins of goat milk, and particularly $\alpha_{S 1}$-casein $(C S N 1 S 1)$, are characterized by a high genetic variability (Palmeri et al., 2014). At least 23 variants are described for CSN1S1 as summarized in Chessa and Caroli (2014). On average $\alpha_{\mathrm{S} 1}$-casein represents only the 10 to $13 \%$ of the total casein contents in goat milk, but its genetic base is the most studied because, depending on the variants, the synthesis level of this casein vary greatly: the strong alleles $\left(A, A_{2}, A_{3}, A^{\prime}, B_{1}, B_{2}, B_{3}, B_{4}, B^{\prime}, C, H, L\right.$, and $\left.M\right)$ produce about $3.5 \mathrm{~g} / \mathrm{L}$ of $\alpha_{\mathrm{S} 1}$-casein each, the intermediate alleles $\left(D_{1}, E\right.$, and $\left.I\right)$ produce 1.1 to $1.8 \mathrm{~g} / \mathrm{L}$, the weak alleles $(D, F$, and $G$ ) produce 0.45 to $0.6 \mathrm{~g} / \mathrm{L}$, and the null alleles $\left(0_{1}, O_{2}, O_{4}\right.$, and $\left.N\right)$ produce no $\alpha_{\mathrm{S} 1}$-casein (Martin et al., 1999). The scientific interest in these genes is due to the importance that particular variants influence nutritional and technological aspects of goat milk. The milk from strong genotypes has a greater aptitude for cheese making properties (Ambrosoli et al., 1988), whereas milk from weak or null genotypes have a potential hypoallergenicity (Bevilacqua et al., 2001). The characterization of the metabolite profile in goat milk has been recently performed by Scano et al. (2014) with the metabolomics approach by using the GC-MS (Marincola et al., 2012) coupled with MVA. These works demonstrated the high capability of a GC-MS approach coupled with the multivariate data analysis to highlight alterations in different metabolic systems. Currently no information is available about 
the metabolomics of milk from goats with different CSN1S1 genotypes. With the aim to elucidate if different genotypes for CSN1S1 influence the metabolome and the pool of hydrophilic metabolites of goat milk and to observe their inter-relationship, we performed a metabolomics method using GC-MS and MVA.

\section{MATERIALS AND METHODS}

\section{Chemicals and Reagents}

Methanol, chloroform, hexane, pyridine, methoxamine hydrochloride, potassium chloride, $N$-methyl$N$-(trimethylsilyl)trifluoroacetamide (MSTFA), lactic acid, alanine, glycine, urea, valine, phosphate, isoleucine, proline, succinic acid, uracil, itaconic acid, methyl maleic acid, serine, malic acid, pyroglutamic acid, creatinine, 2-deossiribose, ribose, levoglucosan, arabinitol, fucose, orotic acid, aconitic acid, 3-phosphogliceric acid altrose, citric acid, fructose, galactose, glucose, mannitol, glucitol, scyllo-inositol, myo-inositol, fructose6-phosphate, mannose-6-phosphate, lactose, cellobiose, and maltose were purchased from Sigma-Aldrich (Milano, Italy). Bidistilled water was obtained from a MilliQ purification system (Millipore, Milan, Italy).

\section{Samples}

Twenty-eight milk samples were obtained from pluriparous Saanen lactating goats at the same lactation stage (DIM $54 \pm 12$ ). Animals were classified on the basis of the CSN1S1 genotype previously typed according to Caroli et al. (2006) as 7 goats classified heterozygous for weak or null alleles $\left(O_{1} O_{1}, F F\right.$, and $\left.F O_{1}\right), 5$ for the intermediate homozygous genotype $(E E)$ and 9 for the intermediate heterozygous genotype ( $6 A E$ and 3 $B E)$, and finally 7 for the strong homozygous genotype $A A$. Animals were kept in pens separated from the rest of the flock and milked twice a day (0700 and $1700 \mathrm{~h}$ ). Diets were formulated to meet energy and protein requirements using the Small Ruminant Nutrition Model (Tedeschi et al., 2010). Each group of animals was fed alfalfa hay (on average $1.1 \mathrm{~kg} / \mathrm{d}$ per goat, as fed), split into 2 feedings (morning and evening), and each animal was individually fed a commercial concentrate $(0.6 \mathrm{~kg} / \mathrm{d}$ per goat, as fed) during both milkings, and beet pulp $(0.11 \mathrm{~kg} / \mathrm{d}$ per goat, as fed $)$. Goats grazed on natural pasture for approximately $3 \mathrm{~h}$ after the morning milking every day. Pasture intake was estimated to be equal to $600 \mathrm{~g}$ of DM based on animal energy requirements.

Individual milk samples were collected from the morning milking and divided in 2 fractions. Samples were refrigerated at $-80^{\circ} \mathrm{C}$ for $10 \mathrm{~d}$ before the metabolomics analysis, whereas fresh samples were analyzed for fat, protein, lactose, and urea content.

\section{Macroscopic Parameters}

Individual milk samples from the morning milking were analyzed for fat, protein, casein, lactose, and MUN using a Milkoscan 6000 instrument (Foss Electric, Hillerød, Denmark) for SCC using a Foss-o-matic 360 instrument (Foss Electric).

\section{Extraction and Derivatization}

Ten milliliters of milk was placed into a Falcon tube and sonicated for $15 \mathrm{~min}$. Then, $0.1 \mathrm{~mL}$ of milk was transferred in an Eppendorf tube and $0.250 \mathrm{~mL}$ of methanol and $0.120 \mathrm{~mL}$ of chloroform were added. After $1 \mathrm{~h}, 0.380 \mathrm{~mL}$ of chloroform and $0.09 \mathrm{~mL}$ of aqueous potassium chloride $0.2 \mathrm{M}$ were added. The obtained suspension was centrifuged at $26,242 \times g$ at $4^{\circ} \mathrm{C}$ for 10 min in an Eppendorf tube. Then, $0.2 \mathrm{~mL}$ of the aqueous layer was transferred into a glass vial and dried by a gentle nitrogen stream and derivatized with $50 \mu \mathrm{L}$ of pyridine containing methoxamine hydrochloride at $10 \mathrm{mg} / \mathrm{mL}$. After $17 \mathrm{~h}, 0.1 \mathrm{~mL}$ of MSTFA was added and after 1-h samples were re-suspended with $0.6 \mathrm{~mL}$ of a solution of 2,2,3,3-d4-succinic acid in hexane at 5 $\mathrm{mg} / \mathrm{L}$.

\section{GC-MS Analysis}

One microliter of derivatized samples was injected splitless into a 6850 gas chromatograph coupled with a 5973 Network mass spectrometer (Agilent Technologies, Santa Clara, CA). The injector temperature was $200^{\circ} \mathrm{C}$. The gas flow rate through the column was $1 \mathrm{~mL} / \mathrm{min}$. The fused silica capillary column was a $0.25 \mu \mathrm{m}$ DB5MS, $30 \mathrm{~m} \times 0.25 \mathrm{~mm}$ ID (J\&W Scientific, Folsom, CA). The initial temperature program was as follows: $10 \mathrm{~min}$ of isothermal heating at $50^{\circ} \mathrm{C}$ then increased to 300 at $10^{\circ} \mathrm{C} / \mathrm{min}$ and held at $300^{\circ} \mathrm{C}$ for $10 \mathrm{~min}$. Ions were generated at $70 \mathrm{eV}$ with electron ionization and were recorded at $1.6 \mathrm{scan} / \mathrm{s}$ over the mass range $m / z 50-550$. The GC-MS data analysis was conducted by integrating each resolved chromatogram peak. Identification of metabolites was performed using the standard NIST08 mass spectra library, a library developed at the Max Planck Institute of Golm, and when available, by comparison with authentic standards (Scano et al., 2014; Pisano et al., 2016). Each sample was analyzed 3 times. 


\section{Multivariate Statistical Data Analysis and Visualization Tools}

For each sample, GC-MS peak intensities of milk derivatized metabolites were normalized to a total sum of 100. An X matrix composed of the analyzed goat milk samples (28), and the chromatographic peak areas (51 variables), was constructed together with a $\mathbf{Y}$ matrix with sample information. Each variable was mean centered and unit variance scaled over all samples, when it presented skew distribution it was log-transformed and the improvement of the symmetry evaluated using the skewness test statistics as implemented in The SIMCA$\mathrm{P}+$ program (version 13.0, Umetrics, Malmö, Sweden). Principal component analysis, partial least squaresdiscriminant analysis (PLS-DA) and its orthogonal variant (OPLS-DA) were performed with SIMCA-P software. The quality of the PLS-DA models and the optimum number of principal components were evaluated based on the cumulative parameters $R^{2} Y$ (classification power) and $\mathrm{Q}^{2} \mathrm{Y}$ (prediction power calculated in cross validation), as implemented in the SIMCA-P+ program. Useful parameters obtained from the PLS-DA models were the variable influence on projection scores and coefficients that indicate the metabolites influence, over all of the validated components, contributing to the separation of sample groups and the comparative metabolites levels in each group (Eriksson et al., 2013).

\section{RESULTS AND DISCUSSION}

\section{Compositional Characteristics of Goat Milk with Different CSN1S1 Genotypes}

The average of the milk fat, protein, urea, and lactose content and SCC for milk with different CSN1S1 genotype is reported in Table 1 . The milk protein content was significantly higher in goats with a strong compared with a low genotype (3.25 vs. $2.92, P<0.01)$, with intermediate genotypes being in the middle, in line with previous reports (Chilliard et al., 2006; Avondo et al., 2015). No other differences in milk composition were found between genotypes even if the fat content was numerically higher $(+14 \% ; P>0.05)$ in milk of goats with strong alleles in agreements with previous observations (de la Torre Adarve et al., 2009; Pagano et al., 2010) that described a greater fat level in goats with strong alleles at the CSN1S1 locus.

\section{GC-MS Analysis}

A total of 28 milk samples were analyzed by GCMS method. After gas-chromatography analysis of milk samples and deconvolution of their mass spectra, 51 metabolites were positively identified across all samples based on their spectral fingerprints and for confirmation compared with authentic standard and retention index matches. Table 2 reports the mass spectrometry characteristics for metabolites found in milk. Identified metabolites were grouped in the following classes: (1) simple sugars such as ribose, fructose, glucose, galactose, fucose, palatinose, altrose, lactose, cellobiose, maltose, levoglucosan, and structurally correlated compounds (i.e., myo-inositol, scyllo-inositol, fructose-6-phosphate, and mannose-6-phosphate or polyols such as arabinitol, mannitol, and sorbitol); (2) organic acids: lactate, succinate, citrate, orotic acid, pyroglutamic acid, and others; (3) AA in their free form: Ala, Val, Gly, Ile, and Ser, the remaining protein AA were either absent in our mixtures or not derivatizable. A total of 10 metabolites were not unambiguously identified.

\section{Multivariate Analysis}

To investigate correlations between compositional and GC-MS data, and to observe samples distribution in the multivariate space, we performed an unsupervised principal component analysis (data not shown). Validation parameters were, respectively, $\mathrm{R}^{2} \mathrm{X}=0.47$ and $\mathrm{Q}^{2}=0.12$. Two outliers, one for the weak null allele class and one from strong allele class, were observed by the means of DModX and Hotelling's $\mathrm{T}^{2}$ analysis and therefore these samples were excluded from the model. With the aim to find metabolites differentiating the different genotype classes, a supervised PLS-DA was performed. In fact, in comparing pairwise the 4 different classes, only the analysis of weak/null alleles with the strong genotype showed a classificatory power. We then performed an OPLS-DA for the study of discriminant

Table 1. Effects of $\alpha_{S 1}$-casein (CSN1S1) genotype on milk yield and composition

\begin{tabular}{|c|c|c|c|c|c|c|c|}
\hline$C S N 1 S 1$ genotype & $\begin{array}{l}\text { Goats } \\
\text { (no.) }\end{array}$ & $\begin{array}{l}\text { Milk yield } \\
\quad(\mathrm{kg} / \mathrm{d})\end{array}$ & $\begin{array}{l}\text { Fat } \\
(\%)\end{array}$ & $\begin{array}{l}\text { Protein } \\
(\%)\end{array}$ & $\begin{array}{l}\text { Lactose } \\
(\%)\end{array}$ & $\begin{array}{c}\log _{10} \mathrm{CCS} \\
(\times 1,000 \text { cells } / \mathrm{mL})\end{array}$ & $\begin{array}{c}\text { MUN } \\
(\mathrm{mg} / \mathrm{dL})\end{array}$ \\
\hline Null/weak $\left(O_{1} O_{1}, F F, F O_{1}\right)$ & 7 & 2.79 & 2.94 & $2.92^{\mathrm{B}}$ & 4.77 & 2.45 & 44.23 \\
\hline Omo-Intermediate $(E E)$ & 5 & 2.65 & 3.72 & $3.20^{\mathrm{AB}}$ & 4.84 & 2.50 & 42.35 \\
\hline Etero-Intermediate $(A E, B E)$ & 9 & 2.44 & 3.10 & $3.13^{\mathrm{AB}}$ & 4.72 & 2.53 & 45.14 \\
\hline Strong $(A A)$ & 7 & 2.70 & 3.35 & $3.25^{\mathrm{A}}$ & 4.76 & 2.65 & 43.39 \\
\hline
\end{tabular}

\footnotetext{
${ }^{\mathrm{A}, \mathrm{B}}$ Means within a column with different superscripts are different $(P<0.01)$.
} 
Table 2. Gas chromatography-mass spectrometry characteristics of goat milk metabolites

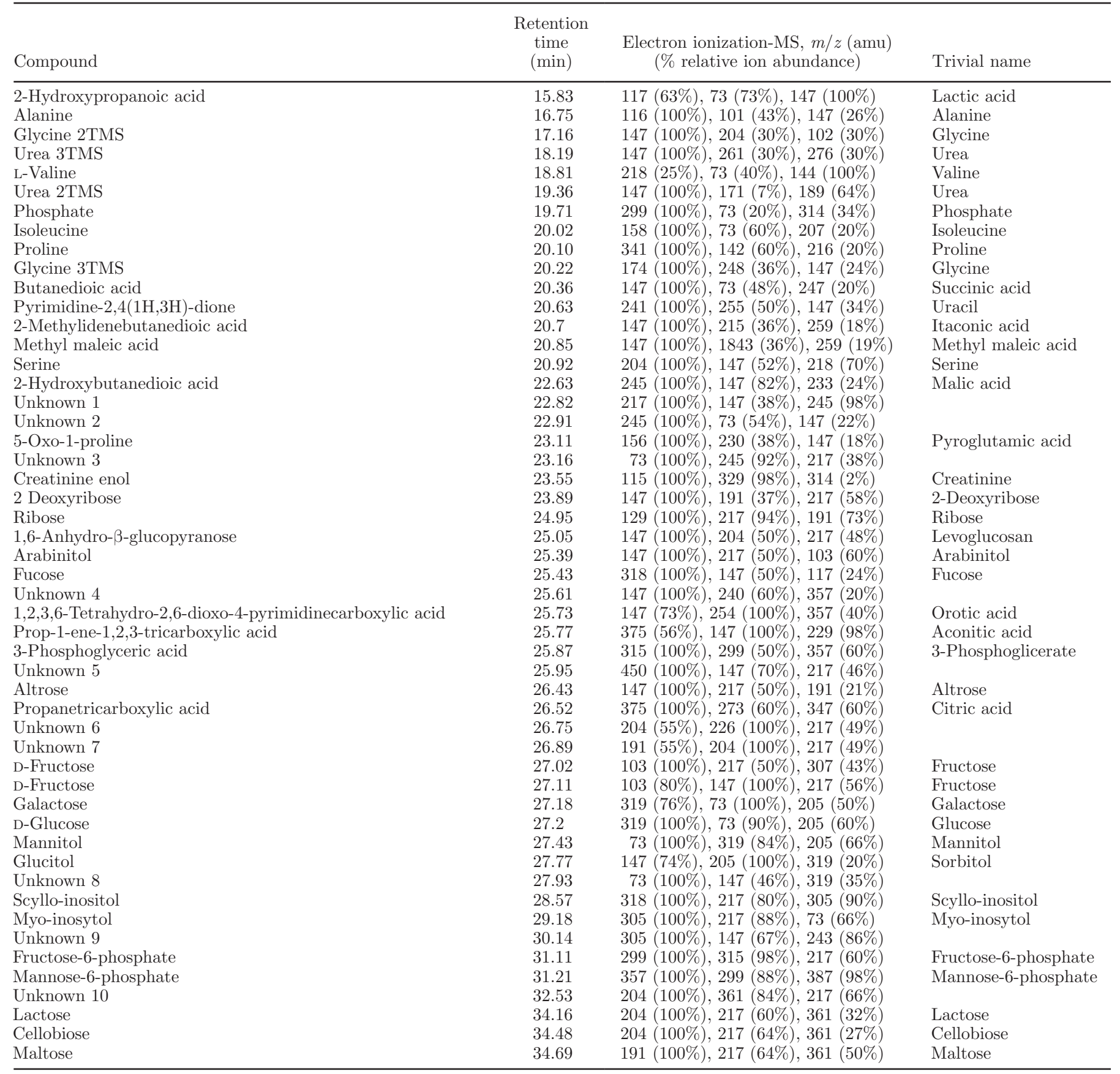

metabolites. The results, depicted as a score plot, are reported in Figure 1. The validation parameters of the analysis were 0.49 for $\mathrm{R}^{2} \mathrm{X}, 0.98$ for $\mathrm{R}^{2} \mathrm{Y}$, and 0.78 for $\mathrm{Q}^{2}$. From the analysis of loadings, the variable influence on projection list indicates that the most discriminant milk metabolites in the class of heterozygous for weak null alleles were levoglucosan, altrose, ribose, arabinitol, serine, fucose, cellobiose, mannose-6-phosphate, and fructose-6-phosphate, whereas for the class of the strong genotype $A A$ they were citric acid and aconitic acid (Table 3 ).

The upregulation of levels of fucose, mannose6-phosphate, and fructose-6-phosphate indicated an alteration of normal carbohydrate metabolism of the weak null allele class, whereas the aldohexose altrose and arabinitol may have originated from microorganisms. Moreover, we found altered levels of ribose for the weak class, whereas Scano et al. (2014) reported 


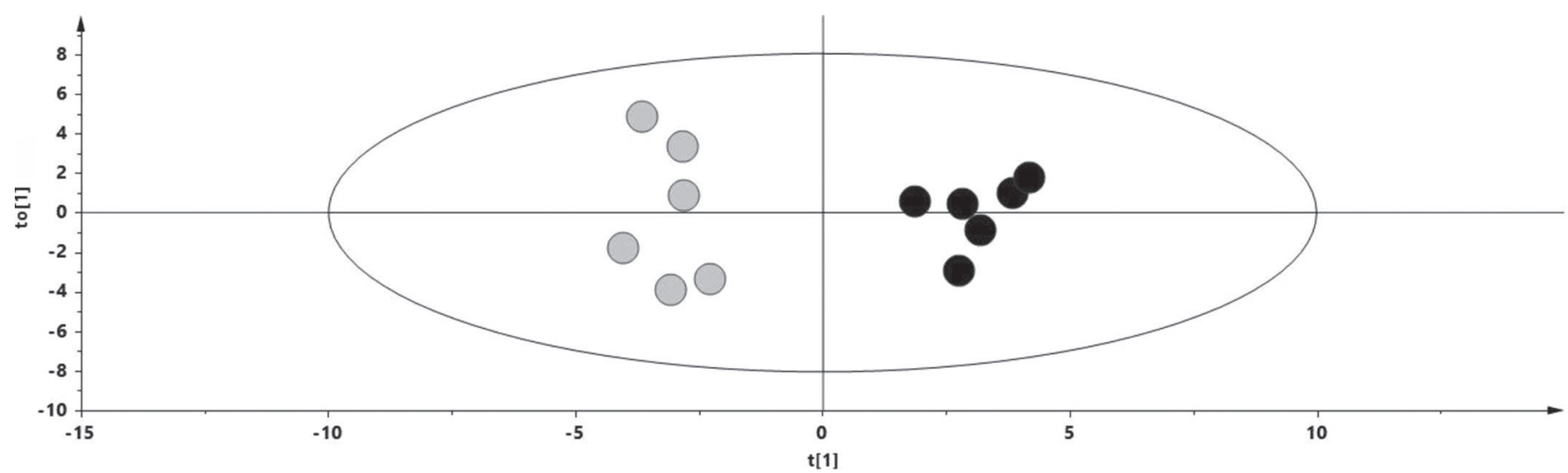

Figure 1. Orthogonal variant of partial least squares-discriminant analysis of GC-MS data. Score plot of model class 0 versus class 3 (black circle and gray circles, respectively); $\mathrm{R}^{2} \mathrm{Y}=0.99$ and $\mathrm{Q}^{2} \mathrm{Y}=0.98$. "t[1]" represents the predictive component, whereas "to" represents the first orthogonal component.

ribose as a discriminant metabolite of goat milk when compared with cow milk. Cellobiose originated from the not completely digested escape fraction of supplement starch is further converted to glucose; furthermore, levoglucosan or 1,6-anhydro- $\beta$-D-glucopyranose is an anhydrosugar derived from starch and cellulose thermal degradation and was found by other authors in headspace of the fresh smoked goat cheese (Guillén et al., 2004). On the other hand, elevated levels of citric acid and aconitic acid for the strong allele class indicated an alterations of tricarboxylic acid cycle. The differences found in goat milk with different genotypes contribute to the explanation of the extreme variability of goat milk composition reported by several authors (Haenlein, 2004; Amigo and Fontecha, 2011) and by our previous observations (Scano et al., 2014). Results reported here may depend not solely on the genotype at the CSN1S1 locus, but that additional single nucleotide polymorphism (either in the casein locus or elsewhere in the genome) can affect the metabolism of the goats used in the study (Tosser-Klopp et al., 2014). Moreover, studies of goat milk and derivatives related to a different polymorphism should be better taken into account

Table 3. Upregulated compounds from the variable influence on projection analysis

\begin{tabular}{ll}
\hline Weak genotypes & Strong genotypes \\
\hline Levoglucosan & Citric acid \\
Altrose & Aconitic acid \\
Ribose & \\
Arabinitol & \\
Serine & \\
Fucose & \\
Cellobiose & \\
Mannose-6-phosphate & \\
Fructose-6-phosphate & \\
\hline
\end{tabular}

besides considering a greater number of milk samples. In conclusion, the hypothesis formulated has been confirmed: the GC-MS analysis coupled with multivariate analysis indicated that polar milk metabolites are strongly related to the different genotype goat classes.

\section{ACKNOWLEDGMENTS}

This study was supported by grants provided by Regione Autonoma della Sardegna "Valorizzazione e innovazione delle produzioni lattiero-casearie caprine in Sardegna. Indagini chimico-fisiche e nutrizionali" (Legge Regionale 7 Agosto 2007, N.7). The authors thank Stefania Chessa from Istituto di Biologia e Biotecnologia Agraria, CNR-Milano (Italy) for the determination of the genotype of the animals.

\section{REFERENCES}

Ambrosoli, R., L. di Stasio, and P. Mazzocco. 1988. Content of as1casein and coagulation properties in goat milk. J. Dairy Sci. 71:2428.

Amigo, L., and J. Fontecha. 2011. Goat milk. 2:484-493 in Encyclopedia of Dairy Science. J. W. Fuquay and P. F. Fox, ed. Academic Press Inc., London, UK.

Avondo, M., P. Pennisi, M. Lanza, R. I. Pagano, B. Valenti, P. Di Gregorio, A. De Angelis, D. Giorgio, andDi Trana, A. 2015. Effect of the as1-casein genotype and its interaction with diet degradability on milk production, milk quality, metabolic and endocrinal response of Girgentana goats. Small Rumin. Res. 123:136-141.

Ballabio, C., S. Chessa, D. Rignanese, C. Gigliotti, G. Pagnacco, L. Terracciano, A. Fiocchi, P. Restani, andCaroli, A. M. 2011. Goat milk allergenicity as a function of $\alpha$ S1-casein genetic polymorphism. J. Dairy Sci. 94:998-1004.

Bevilacqua, C., P. Martin, C. Candalh, J. Fauquant, M. Piot, A. M. Roucayrol, F. Pilla, andHeyman, M. 2001. Goats' milk of defective alpha(s1)-casein genotype decreases intestinal and systemic sensitization to beta-lactoglobulin in guinea pigs. J. Dairy Res. $68: 217-227$.

Caroli, A., F. Chiatti, S. Chessa, D. Rignanese, P. Bolla, andPagnacco, G. 2006. Focusing on the goat casein gene complex. J. Dairy Sci. 89:3178-3187. 
Carroccio, A., F. Cavataio, G. Montalto, D. D'Amico, L. Alabrese, andIacono, G. 2000. Intolerance to hydrolysed cow's milk proteins in infants: Clinical characteristics and dietary treatment. Clin. Exp. Allergy 30:1597-1603.

Chessa, S., and A. M. Caroli. 2014. Polimorfismi genetici lattoproteici caprini e ovini ed effetti sulla qualità del latte. Atti XXI Congresso SIPAOC. 23-27.

Chilliard, Y., J. Rouel, and C. Leroux. 2006. Goat's alpha-s1 casein genotype influences its milk fatty acid composition and delta-9 desaturation ratios. Anim. Feed Sci. Technol. 131:474-487.

de la Torre Adarve, G., E. Ramos Morales, J. M. Serradilla Manrique, F. Gil Extremera, and M. R. Sanz Sampelayo. 2009. Milk production and composition in Malaguena dairy goats. Effect of genotype for synthesis of as1-casein on milk production and its interaction with dietary protein content. J. Dairy Res. 76:137-143.

Eriksson, L., E. Johansson, N. Kettaneh-Wold, J. Trygg, C. Wikström, and S. Wold. 2013. Multi- and megavariate data analysis. Umetrics Academy, Umeå, Sweden.

Guillén, M. D., M. L. Ibargoitia, P. Sopelana, and G. Palencia. 2004. Components detected by headspace-solid phase microextraction in artisanal fresh goat's cheese smoked using dry prickly pear (Opuntia ficus indica). Lait 84:385-397.

Haenlein, G. F. W. 2004. Goat milk in human nutrition. Small Rumin. Res. 51:155-163.

Hosking, C. S., R. G. Heine, and D. J. Hill. 2000. The Melbourne milk allergy study: Two decades of clinical research. Allergy Clin. Immunol. Int. 12:198-205.

Jirillo, F., and T. Magrone. 2014. Anti-inflammatory and anti-allergic properties of donkey's and goat's milk. Endocr. Metab. Immune Disord. Drug Targets 14:27-37.

Le Parc, A., D. C. Dallas, S. Duaut, J. Leonil, P. Martin, andBarile, D. 2014. Characterization of goat milk lactoferrin N-glycans and comparison with the N-glycomes of human and bovine milk. Electrophoresis 35:1560-1570.

Marincola, F. C., A. Noto, P. Caboni, A. Reali, L. Barberini, M. Lussu, F. Murgia, M. L. Santoru, L. Atzori, andFanos, V. 2012. A metabolomic study of preterm human and formula milk by high resolution NMR and GC/MS analysis: Preliminary results. J. Matern. Fetal. Neonatal. Med. 25:62-67.

Martin, P., M. Ollivier-Bousquet, and F. Grosclaude. 1999. Genetic polymorphism of caseins: A tool to investigate casein micelle organization. Int. Dairy J. 9:163-171.

Pagano, R. I., P. Pennisi, B. Valenti, M. Lanza, A. Di Trana, P. Di Gregorio, A. De Angelis, and M. Avondo. 2010. Effect of CSN1S1 genotype and its interaction with diet energy level on milk production and quality in Girgentana goats fed ad libitum. J. Dairy Res. $77: 245-251$.

Palmeri, M., S. Mastrangelo, M. T. Sardina, and B. Portolano. 2014. Genetic variability at $\alpha \mathrm{s}_{2}$-casein gene in Girgentana dairy goat breed. Ital. J. Anim. Sci. 13:116-118.

Pisano, M. B., P. Scano, A. Murgia, S. Cosentino, and P. Caboni 2016. Metabolomics and microbiological profile of Italian mozzarella cheese produced with buffalo and cow milk. Food Chem. 192:618-624.

Scano, P., A. Murgia, F. M. Pirisi, and P. Caboni. 2014. A gas chromatography-mass spectrometry-based metabolomic approach for the characterization of goat milk compared with cow. J. Dairy Sci. 97:6057-6066.

Tedeschi, L. O., A. Cannas, and D. Gene Fox. 2010. A nutrition mathematical model to account for dietary supply and requirements of energy and other nutrients for domesticated small ruminants: The development and evaluation of the Small Ruminant Nutrition System. Small Rumin. Res. 89:174-184.

Tosser-Klopp, G., P. Bardou, O. Bouchez, C. Cabau, R. Crooijmans, Y. Dong, C. Donnadieu-Tonon, A. Eggen, H. C. Heuven, S. Jamli, A. J. Jiken, C. Klopp, C. T. Lawley, J. McEwan, P. Martin, C. R. Moreno, P. Mulsant, I. Nabihoudine, E. Pailhoux, I. Palhière, R. Rupp, J. Sarry, B. L. Sayre, A. Tircazes, J. Wang, W. Wang, W. Zhang, and International Goat Genome Consortium. 2014. Design and characterization of a $52 \mathrm{~K}$ SNP chip for goats. PLoS ONE 9:e86227.

Zhou, S. J., and M. Makrides. 2014. Nutritional adequacy of goat milk infant formulas for term infants: A double-blind randomised controlled trial. Br. J. Nutr. 111:1641-1651. 